\title{
PHASE TRANSFORMATIONS IN CALCITE FROM ELECTRICAL IMPEDANCE MEASUREMENTS
}

\author{
N.S. BAGDASSAROV ${ }^{\mathrm{a} *}$ and A.B. SLUTSKII ${ }^{\mathrm{a}, \mathrm{b}}$ \\ ${ }^{a}$ Institut für Meteorologie und Geophysik, Johann Wolfgang Goethe Universität-Frankfurt, \\ Feldbergstraße 47, 60323 Frankfurt am Main, Germany; \\ ${ }^{\mathrm{b}}$ Vernadskiy Institut of Geochemistry and Analytical Chemistry, Russian Academy of Sciences, \\ Kosygin str. 17, 117975 GSP-1, Moscow, Russia
}

(Received and in final form 3 February 2003)

\begin{abstract}
The phase transformation in calcite I-IV-V and calcite $\Leftrightarrow$ aragonite have been characterized by electrical impedance measurements at temperatures $600-1200^{\circ} \mathrm{C}$ and pressures $0.5-2.5 \mathrm{GPa}$ in a piston cylinder apparatus. The bulk conductivity $\sigma$ has been measured from Argand plots in the frequency range $10^{5}-10^{-2} \mathrm{~Hz}$ in an electric cell representing a coaxial cylindrical capacitor. The synthetic polycrystalline powder of $\mathrm{CaCO}_{3}$ and natural crystals of calcite were used as starting materials. The transformation temperature $T_{c}$ was identified from resistivity-temperature curves as a kink point of the activation energy. At pressure above $2 \mathrm{GPa}$ in ordered phase calcite I, the activation energy $E_{\sigma}$ is c. $1.05 \mathrm{eV}$, and in disordered phase calcite $\mathrm{V} E_{\sigma}$ is c. $0.75 \mathrm{eV}$. The pressure dependence of $T_{c}$ for the rotational order-disorder transformation in calcite is positive for pressures $<1 \mathrm{GPa}$ and negative for pressures $>1 \mathrm{GPa}$. The transformation boundary of calcite 1-IV is observed only during first heating in samples after a long annealing at low temperatures. The activation energy of calcite I $\Leftrightarrow$ IV decreases gradually from 1.8 to $1.05 \mathrm{eV}$ with the pressure increase from 0.5 to $2 \mathrm{GPa}$. The kinetics of calcite $\Leftrightarrow$ aragonite transformation has been monitored by measuring a time-variation of the electrical resistance of a calcite sample at $10^{3} \mathrm{~Hz}$ in the stability P-T field of aragonite. The variation of the impedance correlates with the degree of phase transformation, estimated from X-ray powder diffraction studies on quenched products of experiments. The kinetics of calcite $\Rightarrow$ aragonite transformation may be fitted to the Avrami kinetics with the exponent $m \sim 1-1.5$.
\end{abstract}

Keywords: Order-disorder; Calcite; Aragonite; Phase transition; Electrical impedance; Kinetics

\section{INTRODUCTION}

Structural phase transitions in calcite represent an interesting subject from the point of view of solid state physics, geology and material sciences. For geologists, specializing in carbonate rocks, marble and corals the transitions in calcite may be interpreted as geobarometers (Hacker et al., 1992). In material sciences calcite transformations are important in applications where polymorphs of calcite are used for more effective

*Corresponding author. Fax: +49-(0)6979823280. E-mail: nickbagd@geophysik.uni-frankfurt.de 
solidification of carbonate ceramics (Hosoi et al., 1996; Honma et al., 1998). By fabrication of calcite ceramics the transformation plasticity of $\mathrm{CaCO}_{3}$ may be successfully used to inhibit a solidification process during sintering under hydrothermal hot pressing via calcite-vaterite and calcite-aragonite phase transitions (Hosoi et al., 1996, 1997). In solid state physics the order-disorder transition in calcite represent an unusual example because it is classified as a second-order phase transition, on a mid-way between displacive and order-disorder type transformations (Hagen et al., 1992; Dove, 1997).

Despite a number of publications on phase transformations in $\mathrm{CaCO}_{3}$ there are still many unclear aspects in its phase diagram. The most disputed points are (a) calcitearagonite phase boundary at low pressures and temperatures and kinetics of the phase transformation near this boundary (Jamieson, 1953; Simmons and Bell, 1963; Crawford and Fyfe; 1964; Johannes and Puhan, 1971; Zimmermann, 1971; Crawford and Hoersch, 1972); (b) pressure dependence of the tri-critical order-disorder transition R-3c $\Leftrightarrow$ R-3m (Cohen and Klement, 1973; Mirwald, 1979b); and (c) existence of an intermediate phase at temperatures below $987^{\circ} \mathrm{C}$ (Mirwald, 1979a,b; Redfern et al., 1989; Hagen et al., 1992). The melting curve of $\mathrm{CaCO}_{3}$ which has been established by Irving and Wyllie (1973), was recently revised by in situ X-ray diffraction Raman spectroscopy of calcite at high pressure and temperature (Suito et al., 2001). The general view of the phase diagram of $\mathrm{CaCO}_{3}$ is presented in Fig. 1. The rather poor agreement between the results of various studies on calcite-aragonite transition may be explained by a sluggish kinetics of this transformation at low temperatures, which has been discussed by Carlson (1983). The identification of the field stability of high pressure phases were done using the structural analysis of quench products. Some results of in situ measurements in calcite I-IV-V using DTA-technique

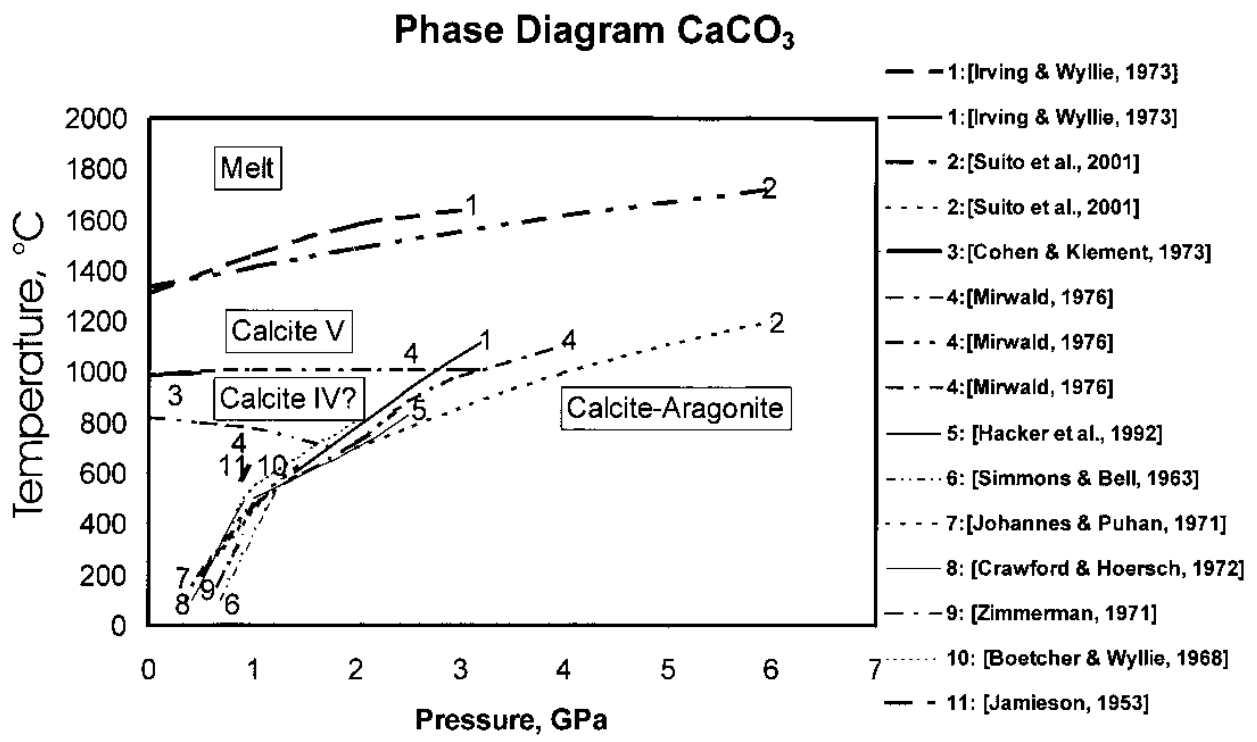

FIGURE 1 Phase diagram of $\mathrm{CaCO}_{3}$ from previous data. In situ determinations of calcite melting curve and calcite $\mathrm{I} \Leftrightarrow$ aragonite transformation provide different results with quench experiments. Pressure dependence of rotational disorder in calcite has been studied at pressures up to $0.5 \mathrm{GPa}$ (Cohen and Klement, 1973) and up to $3 \mathrm{GPa}$ (Mirwald, 1976). At atmospheric pressure the transition temperature has been established from neutron scattering (Dove and Powell, 1989). Erroneous phase Calcite IV is noted by a question mark. 
(Mirwald, 1979a,b) are difficult to interpret due to a weak thermal effect of these transformations. The most reliable data on melting curve and calcite-aragonite transition were obtained with X-ray diffraction (XRD) in multi-anvils and Raman spectroscopy in diamond-anvils (Suito et al., 2001). In this study we exploit a method of electrical impedance measurement as a method to discriminate rotational order-disorder transition in calcite and to estimate kinetics of calcite-aragonite transformation.

Although, the method of electric spectroscopy is a well known method to look at the electronic structure of crystalline solids and glasses, only recently it was shown that the method can provide some additional information on phase transitions and pre-phase transition phenomena associated with structural defect motion. Anomalous behavior of charge carriers prior to the point of a phase transition can be detected either from measurements of an electrical noise caused from fluctuation of electrical resistance (Israeloff, 1996) or from a variation of the polarization exponent (Bagdassarov et al., 2001). In high pressure apparatus this method is easier to realize than other in situ methods characterizing directly a structure of phases, like XRD.

The purpose of this study is to demonstrate the possibility of this method for study the structural phase transition of $\mathrm{CaCO}_{3}$ and to characterize some well known phase boundaries on $\mathrm{CaCO}_{3}$ phase diagram by using the impedance spectroscopy method.

\section{EXPERIMENTS}

\section{Piston-Cylinder}

In this study a conventional piston-cylinder apparatus was used with a pressure cell consisting of $\mathrm{CaF}_{2}$ and boron nitride as a confining medium and a graphite sleeve as a heater (Fig. 2, upper panel). The experiments have been done at pressures up to $2.5 \mathrm{GPa}$ and temperatures up to $1200^{\circ} \mathrm{C}$. The pressure calibration of the cell has been done by the use of some standard point materials: at room temperature the transformations $\mathrm{Bi}$ I-II-III at 2.56 and $2.7 \mathrm{GPa}$ have been used; at high pressure the melting curves of $\mathrm{NaCl}$ and $\mathrm{CsCl}$ have been exploited. The melting points of these salts as a function of pressure up to $2.5 \mathrm{GPa}$ has been determined in situ by electrical conductivity measurements. The performed pressure calibrations is within an accuracy of $\pm 30 \mathrm{MPa}$. The temperature gradient in the cell has been estimated on dummy samples of pressed $\mathrm{Al}_{2} \mathrm{O}_{3}$ powder by the use of three thermocouples. The estimation for a radial temperature gradient is $c a .1^{\circ} / \mathrm{mm}$, for a vertical temperature gradient is $c a .2^{\circ} / \mathrm{mm}$ in the temperature range up to $900^{\circ} \mathrm{C}$. The constant pressure was provided by a servomotor which regulated a position of the piston in a separated hydraulic cylinder. The oil pressure in loading hydraulic rams was maintained within $0.05 \mathrm{MPa}$. Movement of the compressing piston in the autoclave was monitored with a position gauge having precision $\pm 0.001 \mathrm{~mm}$.

\section{Impedance Spectroscopy}

Electrical impedance measurements have been performed with the use of the Solartron ${ }^{\circledR}$ 1260 Phase-Gain-Analyzer interfaced with a PC. The device permits a single sine drive and analysis of a system under test over the frequency range $10 \mu \mathrm{Hz}$ to $32 \mathrm{MHz}$. In high 

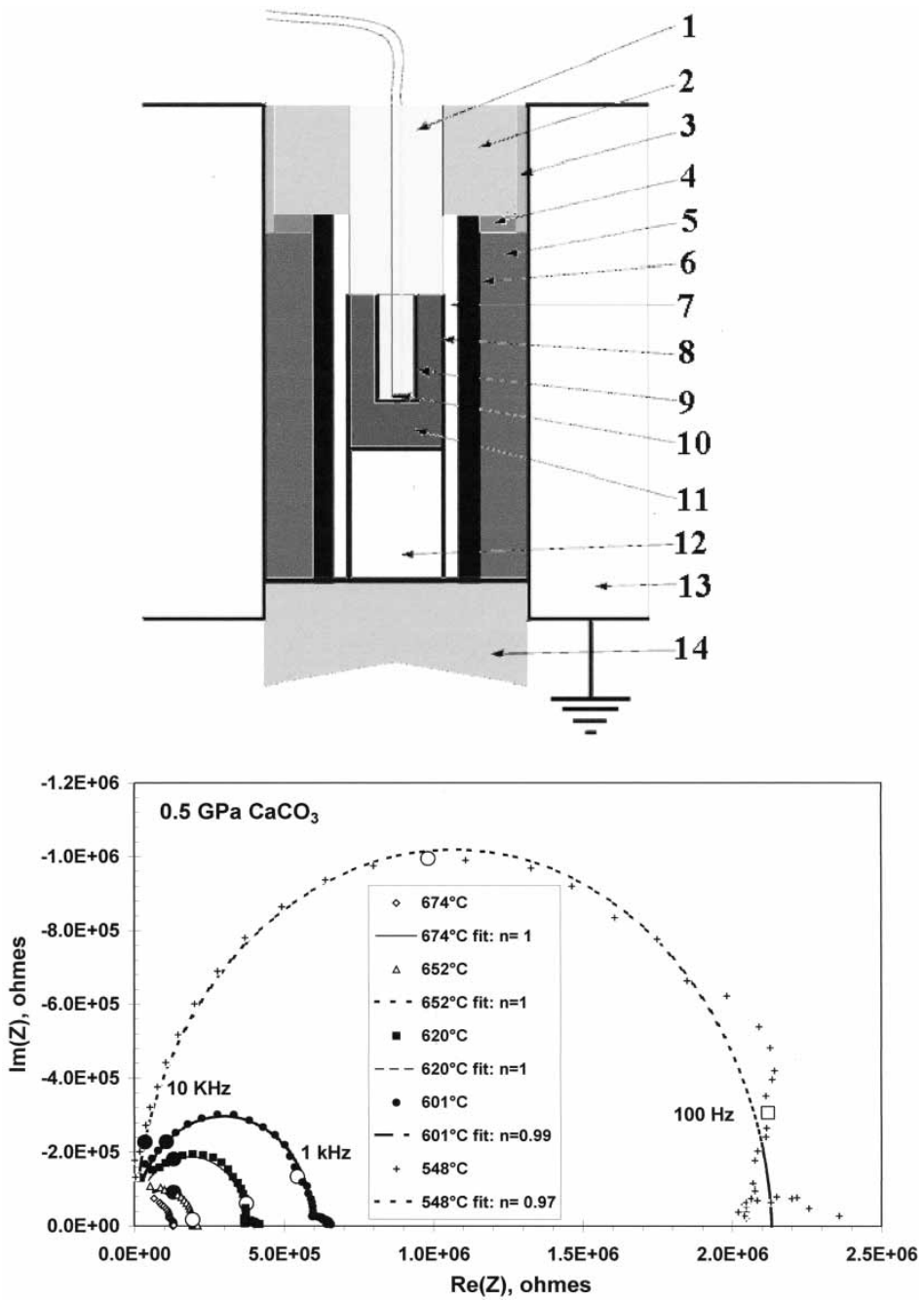

FIGURE 2 Principal scheme of a piston-cylinder cell used for electrical impedance measurements. (Upper panel): 1 - $\mathrm{Al}_{2} \mathrm{O}_{3}$-ceramic; 2 - stainless-steel plug; 3 - sleeve from unfired pyrophillite; 4 - copper ring; 5 - sleeve of $\mathrm{CaF}_{2}$ pressure transmitting medium; 6 - graphite heater; 7 - sleeve of boron nitride; 8 - outer electrode from Pt-tube diameter $4.0 \mathrm{~mm} ; 9$ - inner electrode of Pt-tube diameter $2.2 \mathrm{~mm} ; 10$ - S-type of thermocouple; 11 - sample; 12 - boron nitride; 13 - HM core of the piston-cylinder autoclave; 14 - HM piston. (Lower panel) Argand plot: $\operatorname{Im}(Z) \sim \operatorname{Re}(Z)$ of calcite at $0.5 \mathrm{GPa}$. The first and the second arcs were fitted to Eq. (2). The parameter $\tau_{1}$ for presented curves are as follows: $548^{\circ} \mathrm{C} \tau_{2}=1.35 \cdot 10^{-4} \mathrm{~s}, 601^{\circ}-$ $3.62 \cdot 10^{-5}, 620^{\circ}-2.27 \cdot 10^{-5}, 652^{\circ}-1.56 \cdot 10^{-5}, 674^{\circ}-7.44 \cdot 10^{-6}$. Enlarged symbols on the Argand-plots mark frequencies of the measurements: closed circles $-10 \mathrm{kHz}$, open circles $-1 \mathrm{kHz}$, open square $-100 \mathrm{~Hz}$.

pressure experiments $1 \mathrm{~V}$ sine signal was applied in frequency range $0.01 \mathrm{~Hz}$ to $100 \mathrm{kHz}$. A cell for electrical impedance measurements represents a coaxial cylindrical capacitor with a geometric factor 5-7 cm filled with a sample under test. The exact geometric factor of a cell has been evaluated independently from calibration measurements on $\mathrm{NaCl}$ solutions $(0.01-3 \mathrm{M})$ at $22^{\circ} \mathrm{C}$ and pressure $0.1 \mathrm{MPa}$. For these purposes a cylindrical gap between two Pt-electrodes (made of Pt-tubes $0.1 \mathrm{~mm}$ in thickness) has been filled with a $\mathrm{NaCl}$-solution of a known molar concentration. The measured 
conductivity of $\mathrm{NaCl}$-solutions has been compared with the table values. The difference between a calculated geometric factor of the cylindrical capacitor

$$
G=2 \pi \frac{L}{\ln (D / d)}
$$

and a measured geometric factor by using standard solutions was about $25 \%$. In Eq. (1) $D$ is the diameter of an outer electrode, $d$ is the diameter of an inner electrode, $L$ is the length of inner cylinder. The main advantage of the use of a coaxial cylinder geometry before a parallel plate geometry is a negligible change of the geometric factor under loading the sample (Slutskii, 1969).

During impedance measurements the press was separated from the ground of the Solartrom 1260. One wires of Pt-thermocouple and the mass of the high pressure autoclave were used to connect the measuring device and the cell electrodes. Before doing the high pressure experiments a measuring cell has been calibrated for a short circuit and for an open circuit impedances in a frequency range $1 \mathrm{MHz}$ to $0.01 \mathrm{~Hz}$. A typical AC-resistance of the cell to a short circuit is $0.4 \Omega$. These calibrations have been taken into account in final calculations of the electrical impedance as a function of frequency. At high pressure and temperature the measurements of the electrical impedance were conducted without an automatic temperature control in order to reduce electrical noise of the temperature controller. Each measured frequency scan of the complex resistance has been fitted to the expression as follows (e.g. Jonscher, 1999a,b):

$$
Z^{*}=\frac{R_{1}}{1+\left(j \cdot \omega \cdot \tau_{1}\right)^{p}}+\frac{R_{2}}{1+\left(j \cdot \omega \cdot \tau_{2}\right)^{n}},
$$

where the first and the second terms are responsible for low and high frequency dielectric losses, i.e. to two arcs on an Argand-type of diagram describing bulk and electrode polarization processes. In Eq. (2) parameters $0<p, n<1$ are empirical constants characterizing a deviation of the observed dielectric loss peaks from a Debyetype function. Parameters $\tau_{2}, R_{2}$ and $n$ are related to the bulk properties of a sample, $\tau_{1}, R_{1}$ and $p$ are related to the sample-electrode polarization. The bulk dc-conductivity of a sample is calculated from $\sigma_{\mathrm{DC}}=1 /\left(R_{2} \cdot G\right)$. The temperature dependence of the bulk dc-conductivity usually follows an Arrhenius-type of dependence

$$
\sigma_{\mathrm{DC}} \cdot T=\sigma_{0} \cdot e^{-\left(E_{\sigma} / k T\right)}
$$

where $T$ is in Kelvin, $k$ is the Boltzmann's constant, $\sigma_{0}$ is the pre-exponential factor, $E_{\sigma}$ is the activation energy of the electrical conductivity, characterizing an energetic barrier for the movement of charge carriers, i.e. lattice defects. The parameter $n$ in Eq. (2) describes a power law dispersion in a situation when the short range displacements of lattice defects become coupled with ionic environment. In ionic conductors with the increasing temperature $n$ decreases from 1 to 0.5-0.6 (Sidebottom et al., 1995). In different temperature intervals the accuracy of the fitting parameters for the first term in the right hand side of Eq. (2) varies significantly. Thus, $p, \tau_{1}$ and $R_{1}$ in Eq. (2) were not used in analysis of the experimental data. 
Previous works on measuring electrical conductivity of calcite were done at room pressure by using the impedance spectroscopy method (Rao and Rao, 1968), and at $4 \mathrm{MPa} \mathrm{CO}$ (Mirwald, 1979b) on single crystals. In single crystals the impurity conductance mechanism play a major role at temperatures below c. $300^{\circ} \mathrm{C}$, and the electrical conductivity from this mechanism $\sigma$ has activation energies $E_{\sigma} \sim$ c. 0.11 and $0.15 \mathrm{eV}$ in directions parallel and normal to $c$-axe, respectively. Intrinsic conduction has activation energies, $E_{\sigma} \sim 0.91$ and $1.05 \mathrm{eV}$, respectively at $T$ above $300^{\circ} \mathrm{C}$ (Rao and Rao, 1968). Mirwald (1979b) pointed out several temperature intervals where an abrupt change of the activation energy was observed: at $400-725^{\circ} \mathrm{C} E_{\sigma}=0.9-1.05 \mathrm{eV}$, at $725-800^{\circ} \mathrm{C} \sim 0.2 \mathrm{eV}$, at $800-935^{\circ} \mathrm{C} E_{\sigma} \sim 1.5 \mathrm{eV}$, and above $935^{\circ} \mathrm{C} E_{\sigma} \sim 2 \mathrm{eV}$. From the thermoelectric voltage measurements Mirwald (1979) concluded the electronic character of the conductivity in calcite. To the best of the authors knowledge, at high pressures any measurements of the calcite conductivity have not been reported yet.

\section{IMPEDANCE MEASUREMENTS AND ORIENTATIONAL ORDER-DISORDER TRANSITION IN $\mathrm{CaCO}_{3}$}

Typical scans obtained at $0.5 \mathrm{GPa}$ on $\mathrm{CaCO}_{3}$ are shown in Fig. 2 (lower panel). The experimental data of the electrical impedance were fitted to Eq. (2), the bulk resistance of a sample has been obtained as function of temperature. The starting sample of $\mathrm{CaCO}_{3}$ was heated from c. $500-850^{\circ} \mathrm{C}$ (depending on pressure) to c. $1200^{\circ} \mathrm{C}$ with a constant rate c. $1.5^{\circ} / \mathrm{min}$. Then samples were annealed at temperature above $1100^{\circ} \mathrm{C}$ for $12 \mathrm{~h}$, cooled down again with the same rate and annealed at temperature below $800^{\circ} \mathrm{C}$ for $12 \mathrm{~h}$. The measured bulk electrical conductivity are presented in Figs. 3 and 4 on graphs $\ln (\sigma x T) \sim 1 / T, \mathrm{~K}$. The transformation temperature $\left(T_{c}\right)$ for phase transition $\mathrm{R}-3 \mathrm{c} \Leftrightarrow \mathrm{R}-3 \mathrm{~m}$ was estimated as a point on Arrhenius plots where the slope $\ln (\sigma x T)$ vs $1 / T, \mathrm{~K}$ is changed.

Table I summaries the experimental results of $T_{c}$ estimations. Tri-critical R-3c $\Leftrightarrow$ $\mathrm{R}-3 \mathrm{~m}$ order-disorder phase transition in alkaline earth carbonates consists of disordering of $\mathrm{CO}_{3}$ groups with respect to $60^{\circ}$ rotations about their threefold axes (e.g. Lander, 1949). Kinetics of the tri-critical order-disorder transformation $\mathrm{R}-3 \mathrm{c} \Leftrightarrow \mathrm{R}-3 \mathrm{~m}$ in $\mathrm{CaCO}_{3}$ is instantaneous. There is only small temperature hysteresis in the kink point of the activation energy by crossing this phase boundary on cooling and heating. This reflects the fact that this transformation in calcite represents a crossover behavior between displacive and order/disorder phase transitions (Dove, 1997). In terms of scalar displacements of atoms it means that the "hump height" of the double-well one site potential is of the same magnitude as the interaction between neighboring atoms (Padlewski et al., 1992).

The existence of the phase transition at temperatures $800-900^{\circ} \mathrm{C}$ at elevated pressures is not clear from the electrical impedance experiments. Only one experimental work using DTA has demonstrated the firm existence of this phase boundary Calcite $\mathrm{I} \Leftrightarrow$ Calcite IV (Mirwald, 1979a). In the heating cooling runs the small decrease of the activation energy $\ln (\sigma x T) \sim 1 / T, \mathrm{~K}$ can be observed in the first cycle (Figs. 3 and 4 ). After second heating-cooling cycle the change of the activation energy becomes smaller. The increase of the annealing time at temperature below $800^{\circ} \mathrm{C}$ results in smoothing of Arrhenius plots in the temperature interval up to $\mathrm{R}-3 \mathrm{c} \Leftrightarrow \mathrm{R}-3 \mathrm{~m}$ transformation. With the pressure the temperature points of transformations between Calcite I-IV(?) and Calcite IV-V becomes closer. If the phase IV is interpreted as a "kinetic" and par- 
$\mathrm{CaCO}_{3} 0.5$ and $1 \mathrm{GPa}$
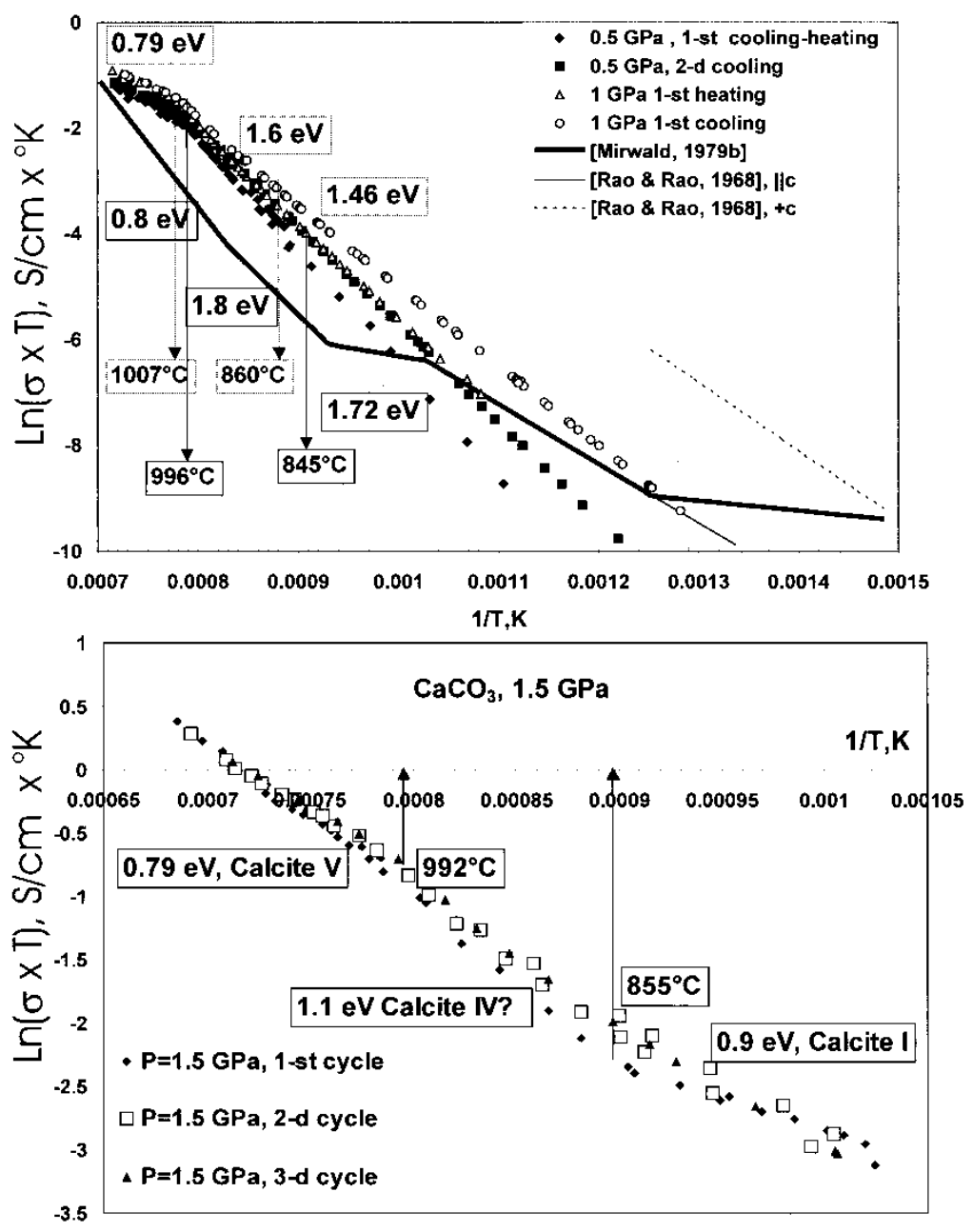

FIGURE 3 (Upper panel) $\sigma x T$ in calcite and determination of $T_{c}$ temperature for the calcite transformation R-3c $\Rightarrow$ R-3m at 0.5 and 1 GPa. Thick solid line represents the measurements of Mirwald (1979b) at $4 \mathrm{MPa} \mathrm{CO}_{2}$ pressure, thin solid and dotted lines are extrapolated results of Rao and Rao (1968). (Lower panel) $\sigma x T$ in calcite and phase transitions at $1.5 \mathrm{GPa}$. Heating of calcite through the phase transition leads to a halving of the unit cell in the $c$-direction and a decrease of the activation energy of electrical conductivity for $\Delta E_{\sigma} \sim 0.8-1 \mathrm{eV}$. At the phase transition point the activation energy changes from 1.8 to $0.8 \mathrm{eV}$ at $0.5 \mathrm{GPa}$ and from 1.6 to $0.8 \mathrm{eV}$ at $1 \mathrm{GPa}$. The bending point on the Arrhenius plot $\ln (\sigma x T) \sim 1 / T$, $\mathrm{K}$ is reversible. $T_{c}$ was obtained on synthetic calcite samples as well as on natural crystals.

tially disordered phase, it would be logic to assume that pressure plays against stability of this phase. The identification of Calcite I $\Leftrightarrow$ Calcite IV transformation temperature from electrical conductivity data is not obvious. The change in the activation energy between 800 and $900^{\circ} \mathrm{C}$ after 2-d cycle of cooling-heating is practically unobservable. The existence of this kink in the slope $\ln (\sigma) \sim 1 / T, \mathrm{~K}$ depends on the cooling rate of the sample from the stability field of R-3m phase and appears mostly during subsequent heating after a short annealing time at temperatures below $800^{\circ} \mathrm{C}$. At this point we agree with Redfern et al. (1989) that the nature of the Calcite I $\Leftrightarrow$ IV phase 


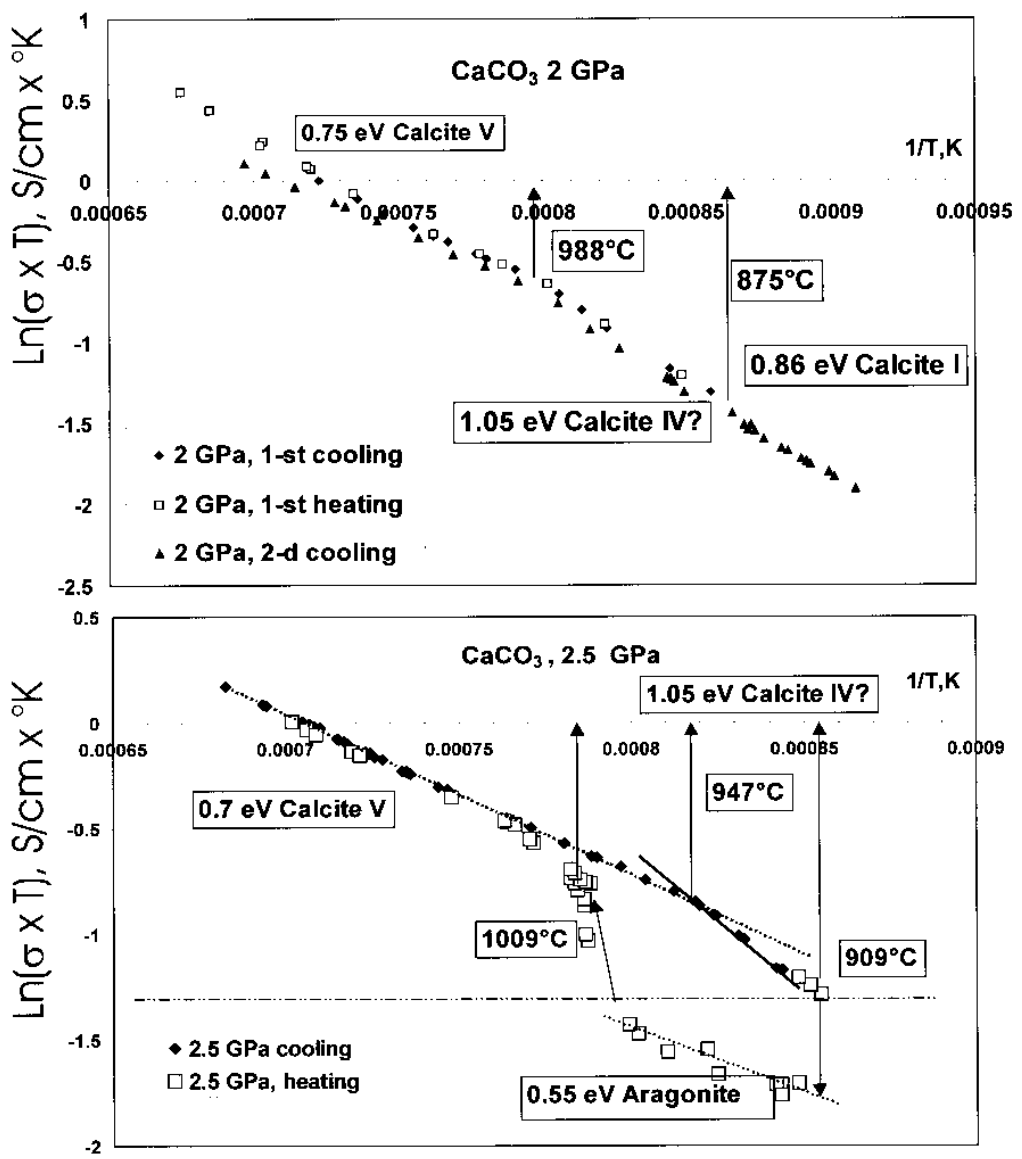

FIGURE 4 (Upper panel) Bulk electrical conductivity $\sigma x T$ and phase boundaries in Calcite at $2 \mathrm{GPa}$. (Lower panel) Transformation of Calcite $\Leftrightarrow$ Aragonite and ordered $\Leftrightarrow$ orientational disordered phases of Calcite at $2.5 \mathrm{GPa}$. Conductivity of Aragonite is lower than Calcite. The sudden drop of conductivity during cooling corresponds to the transformation of Calcite into Aragonite. The time scale of the complete transformation at $2.5 \mathrm{GPa}$ is about $0.5 \mathrm{~h} . T_{c}$ of ordered-orientational disordered Calcite drops with pressure at $P>1 \mathrm{GPa}$.

boundary probably kinetic and connected with the retained disorder of $\mathrm{CO}_{3}$ groups within R-3c phase. Alternatively, the interpretation of inelastic scattering on calcite ordered structure do not exclude an existence of another possible structure below $987^{\circ} \mathrm{C}$ and above $730^{\circ} \mathrm{C}$ with a free energy smaller than disordered phase (Hagen et al., 1992).

According to the present results at high temperatures the transition from $\mathrm{R}-3 \mathrm{c}$ to $\mathrm{R}-3 \mathrm{~m}$ phase is marked by a distinct decrease of the activation energy to c. $0.75 \mathrm{eV}$, which was not observed in the work of Mirwald (1979b) who reported much higher activation energy of the electrical conductivity $E_{\sigma} \sim$ c. $2 \mathrm{eV}$ (Fig. 3, upper panel). The transformation temperature of the $\mathrm{R}-3 \mathrm{c} \Leftrightarrow \mathrm{R}-3 \mathrm{~m}$ phase transition is identified from the electrical impedance measurements with a high confidence and reproducibility. The experiment at $2.5 \mathrm{GPa}$ (Fig. 4, lower panel) revealed some interesting features of $\mathrm{R}-3 \mathrm{c} \Leftrightarrow \mathrm{R}-3 \mathrm{~m}$ transformation near the calcite-aragonite equilibrium boundary. Upon 
TABLE I $T_{c}$ obtained from electrical conductivity measurements

\begin{tabular}{lccc}
\hline$P(\mathrm{GPa})$ & Calcite $\Leftrightarrow$ Aragonite & Calcite $1 \Leftrightarrow I V$ & $R-3 m \Leftrightarrow R-3 c T_{c}\left({ }^{\circ} \mathrm{C}\right)$ \\
\hline 0.5 & & $845 \pm 5$ & $996 \pm 2$ \\
1.0 & $680 \pm 10$ & $860 \pm 5$ & $1007 \pm 3$ \\
1.5 & $955 \pm 5$ & $992 \pm 3$ \\
2.0 & $909 \pm 2$ & $875 \pm 5$ & $988 \pm 4$ \\
2.5 & & $947 \pm 4$ \\
\hline
\end{tabular}

Note: $T_{c}$ of $\mathrm{R}-3 \mathrm{c} \Leftrightarrow \mathrm{R}-3 \mathrm{~m}$ transition in $\mathrm{CaCO}_{3}$ reported by Redfern et al. (1989) at $0.1 \mathrm{MPa}$ is $987 \pm 5^{\circ} \mathrm{C}$. The reported values of $T_{\mathrm{c}}$ for Calcite I $\Leftrightarrow$ Calcite IV and Calcite $\mathrm{R}-3 \mathrm{c} \Leftrightarrow \mathrm{R}-3 \mathrm{~m}$ are average values obtained on 3 different samples ( 2 chemical powders, 1 natural crystal) during 3 consequently repeated heating and cooling cycles. Values of $T_{c}$ for Calcite $\Leftrightarrow$ Aragonite transformation are maximum temperatures at which Calcite has been transformed in Aragonite in annealing experiments.

TABLE II Activation energy of $E_{\sigma}$ of dc-conductivity in $\mathrm{CaCO}_{3}(\mathrm{eV})$

\begin{tabular}{lccc}
\hline Pressure $(\mathrm{GPa})$ & Calcite $I$ & Calcite $I V ?$ & Calcite V \\
\hline 0.5 & $1.72 \pm 0.05$ & $1.80 \pm 0.05$ & $0.80 \pm 0.02$ \\
1.0 & $1.46 \pm 0.04$ & $1.60 \pm 0.05$ & $0.79 \pm 0.02$ \\
1.5 & $0.90 \pm 0.05$ & $1.11 \pm 0.04$ & $0.78 \pm 0.02$ \\
2.0 & $0.86 \pm 0.04$ & $1.05 \pm 0.02$ & $0.75 \pm 0.03$ \\
2.5 & $* 0.55 \pm 0.02$ & $1.05 \pm 0.02$ & $0.70 \pm 0.02$ \\
& (Aragonite) & & \\
\hline
\end{tabular}

Note: The reported values of $E_{\sigma}$ are average values obtained on 3 different samples during 3 consequently repeated heating and cooling cycles.

cooling R-3m phase transforms in R-3c phase with a characteristic increase of the activation energy from 0.7 to $1.05 \mathrm{eV}$, and then into aragonite $(\mathrm{E} \sigma \sim 0.55 \mathrm{eV})$. The latter transformation accompanied with a drop of the electrical conductivity for about 1 order of magnitude. The reverse transformation of aragonite into calcite occurs with a significant temperature hysteresis and directly in the phase R-3m without intermediate transformation into ordered R-3c phase The new puzzle coming from the present study is a change of the slope of $\mathrm{R}-3 \mathrm{c} \Leftrightarrow \mathrm{R}-3 \mathrm{~m}$ phase boundary from positive to negative one at pressures above $1 \mathrm{GPa}$. The DTA results of Cohen and Klement (1973) indicate the slope $31 \mathrm{~K} / \mathrm{GPa}$. Mirwald (1976) reported that the slope becomes smaller above $1 \mathrm{GPa}$ c. $20 \mathrm{~K} / \mathrm{GPa}$. In Redfern et al. (1989) the slope is considered to be practically zero at a first order approximation. According to our data at pressures above $1 \mathrm{GPa} T_{\mathrm{c}}$ decreases. This has been confirmed on different starting materials and in experiments consisting of 3-4 heating cooling cycles with different annealing times at temperature above $1100^{\circ} \mathrm{C}$ and below $800^{\circ} \mathrm{C}$. The nature of this decrease may be in a closeness of $\mathrm{R}-3 \mathrm{c} \Leftrightarrow \mathrm{R}-3 \mathrm{~m}$ orientational disorder phase boundary to the aragonite phase boundary and a coupling phenomena between two phase transitions. Alternative explanation suggests an existence of a displacive phase transition in the disordered phase at pressures above c. $1.5 \mathrm{GPa}$ by analogy with the high pressure transformation in monoclinic calcite II at low temperatures.

Calcite represents a dielectric material. In dielectrics the fitting parameter $\tau_{2}$ in Eq. (2) characterizes the relaxation time of bulk charge carriers: (a) dipole rotation, and (b) space charges, consisting of impurity atoms and Ca-vacancies (Bogris et al., 1998). The dielectric relaxation time estimated at each temperature also obeys the Arrhenian type of equation

$$
\tau_{2}=\tau_{0,2} \cdot e^{-\left(E_{a}+P \cdot v_{m}\right) / k \cdot T}
$$


TABLE III Activation energy of dielectric relaxation time $\tau_{2}$ in Calcite I below $800^{\circ} \mathrm{C}$

\begin{tabular}{lcc}
\hline$P(\mathrm{GPa})$ & $E_{a}(\mathrm{eV})$ & $\tau_{0,2}\left(10^{-13} \mathrm{~s}\right)$ \\
\hline 0.5 & $1.43 \pm 0.05$ & $1.9 \pm 0.3$ \\
1.0 & $1.17 \pm 0.02$ & $2.1 \pm 0.1$ \\
1.5 & $1.15 \pm 0.02$ & $3.4 \pm 0.2$ \\
2.0 & $1.09 \pm 0.03$ & $8.1 \pm 0.5$ \\
\hline
\end{tabular}

Note: $E_{a}$ extrapolated to atmospheric pressure $\sim 1.47 \mathrm{eV}$, the activation volume $\sim-20 \mathrm{~cm}^{3} / \mathrm{mol}^{\text {. }}$

where $P$ is the pressure, $v_{m}$ is the activation volume, $E_{a}$ is the activation energy of the dielectric relaxation and $\tau_{0,2}$ is the pre-exponential factor. $\tau_{2}$ has been calculated from the measured electrical impedance frequency scan at each temperature and pressure by using Eq. (2). Multi-linear regression analysis of these data permits to evaluate $E_{a}$ and $v_{m}$ according to Eq. (4). The results of the activation energy of the dielectric relaxation time are presented in Table III. According to the obtained results at $T<800^{\circ} \mathrm{C}$ and $E_{a} \sim 0.75-0.8 E_{\sigma}$, the pre-exponential factor $\tau_{0,2} \sim 2-8 \cdot 10^{-13} \mathrm{~s}$, and the activation volume $v_{m}$ is negative $\sim-20 \mathrm{~cm}^{3} / \mathrm{mol}\left(-0.34 \cdot 10^{-28} \mathrm{~m}^{3}\right.$ volume per migrating particle). The activation energy of the dielectric relaxation process is much larger than the simple dipole rotation and migration in a single crystal calcite: $E_{a} \sim 0.66 \mathrm{eV}$ and $v_{m} \sim 3 \cdot 10^{-28} \mathrm{~m}^{3}$ (Grammatikakis et al., 2001), which indicate a bulk charge transport mechanism in a form of Ca-vacancies and impurities migration coupled with a weak dipole relaxation.

The main difference with the previous measurements of the electrical conductivity in calcite is a decrease of the activation energy of the electrical conductivity at the order/disorder transition. In the ordered calcite along the $z$-axis the $\mathrm{CO}_{3}^{2-}$ groups belonging to the same layer are of the same orientation, and those that belong to adjacent layers are of different orientation. In disordered calcite the orientation of $\mathrm{CO}_{3}^{2-}$ groups in adjacent layers is indistinguishable. The loss of the orientational order of $\mathrm{CO}_{3}^{2-}$ groups along the $z$-axis may affect the activation energy of the electrical conductivity as follows. If a Ca-vacancy or an impurity atom migrates along the $z$-axis in a single crystal of the ordered phase there is an additional polarization energy $\sim 0.7 \mathrm{eV}$ (Mandell and Rock, 1998) due to the shifted charge distribution of two adjacent $\mathrm{CO}_{3}^{2-}$ belonging to two adjacent layers along the $z$-axis. This charge shift acts as an electric dipole, thus, a migrating charge carrier has to overwhelm the polarization energy of this dipole. This energy contributes to the barrier for a point charge migration and included in the activation energy of the electric conductivity of R-3c phase. In the R-3m phase this contribution to the activation energy vanishes. In a polycrystalline calcite the energetic effect from dipole polarizations must be weaker than in a single crystal.

\section{CALCITE-ARAGONITE TRANSITION}

The phase transition Calcite $\Leftrightarrow$ Aragonite ( $\mathrm{R}-3 \mathrm{c} \Leftrightarrow \mathrm{Pmcn}$ ) is of a reconstructive type, which means that the characteristic time of this phase transition is determined by a self diffusion coefficients of $\mathrm{Ca}$ and $\mathrm{O}$. In polycrystalline materials the situation is also complicated by grain boundary diffusion coefficients which determine grain boundary nucleation rate of a new phase (Liu and Yund, 1993). Depending on temperature the 


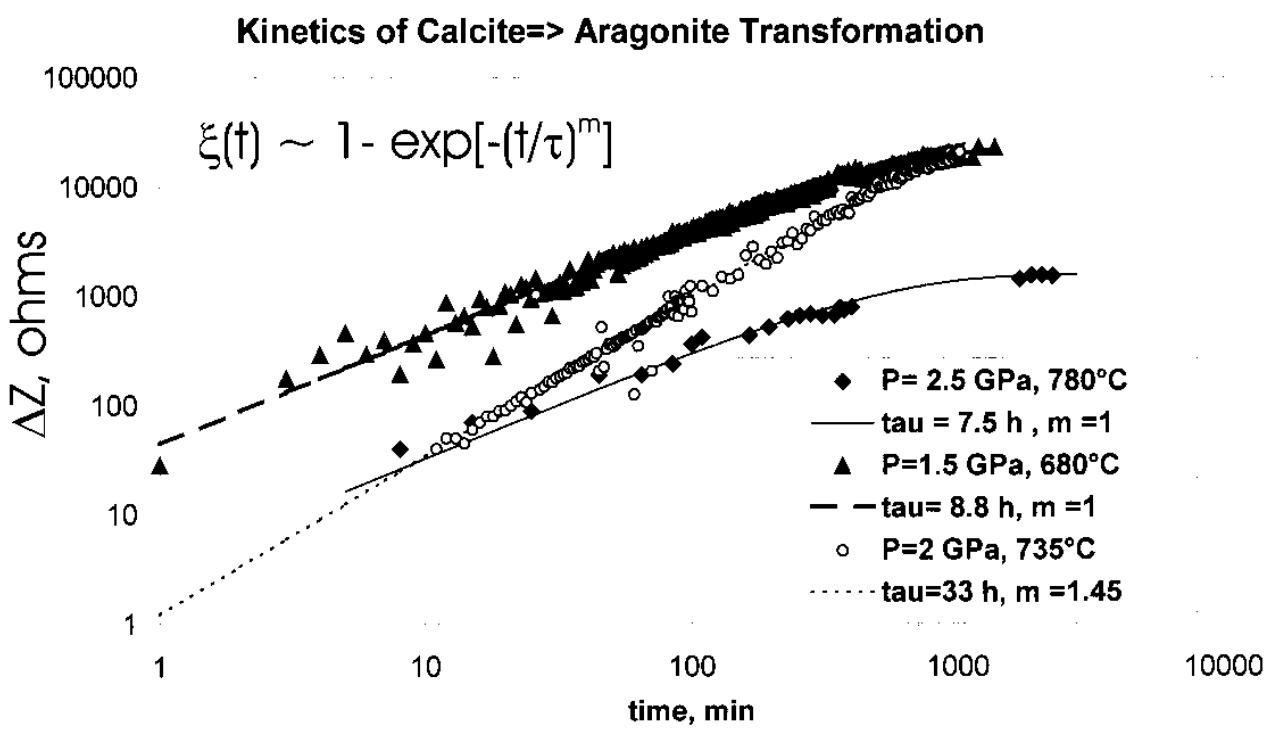

FIGURE 5 After quenching of annealed samples the proportion of Calcite/Aragonite was estimated in them from peak intensities on a diffractogramm. The time constant $\tau$ in Eq. (2) is related to the characteristic time of the phase transformation. Kinetics of Calcite $\Rightarrow$ Aragonite transformation has been estimated from the monitoring of a resistance - time dependence $\Delta Z(t)$. Calcite sample was cooled down and kept in the stability field of Aragonite during a long time until the electrical bulk resistance reaches a steady state value corresponding to the accomplished phase transformation. The measurements of the resistance were done at a fixed frequency $1 \mathrm{kHz}$. The data were fitted to the equation Eq. (5).

characteristic time $(\tau)$ of the phase transformation may vary in a wide range (Hacker et al., 1992). The effects of pressure, temperature, grain size and deviation of pressure above an accepted equilibrium boundary have been analyzed previously (Carlson, 1983). In this study a few experiments have been performed to determine a characteristic time $\tau$ of the phase transformation Calcite $\Rightarrow$ Aragonite in order to demonstrate a possibility of the use of electrical impedance measurements for monitoring a degree of this phase transformation. Calcite was brought into the stability field of Aragonite by crossing the phase boundary for $\delta P-\delta T$, and a relative change of the electrical resistance was monitored as a function of time. The final product of the transformation was analyzed from diffractogramms using X-ray standards of pure calcite and aragonite. The proportion of two phase in final products were determined from the relative intensities of the highest peaks [111] for calcite and [104] for aragonite scaled to the difference in their symmetry groups. Results of the electrical impedance measurements during the transformation of calcite into aragonite are presented in Fig. 5. A degree of the phase transformation $\xi(t)$ corresponds in the first approximation to a relative variation of the electrical resistance $\Delta Z(t)=Z(t)-Z(0)$ and has been fitted to the Avrami-type equation

$$
\Delta Z(t)=\Delta Z_{\infty} \cdot\left[1-\exp \left(-(t / \tau)^{m}\right)\right]
$$

where $\Delta Z(t)$ and $\Delta Z_{\infty}$, stand for an excess of the electrical resistance of aragonite in comparison with calcite at time $t$ and in a steady state, respectively. $\tau$ is a characteristic time of the transformation and $m$ is an empirical parameter, which generally depends 


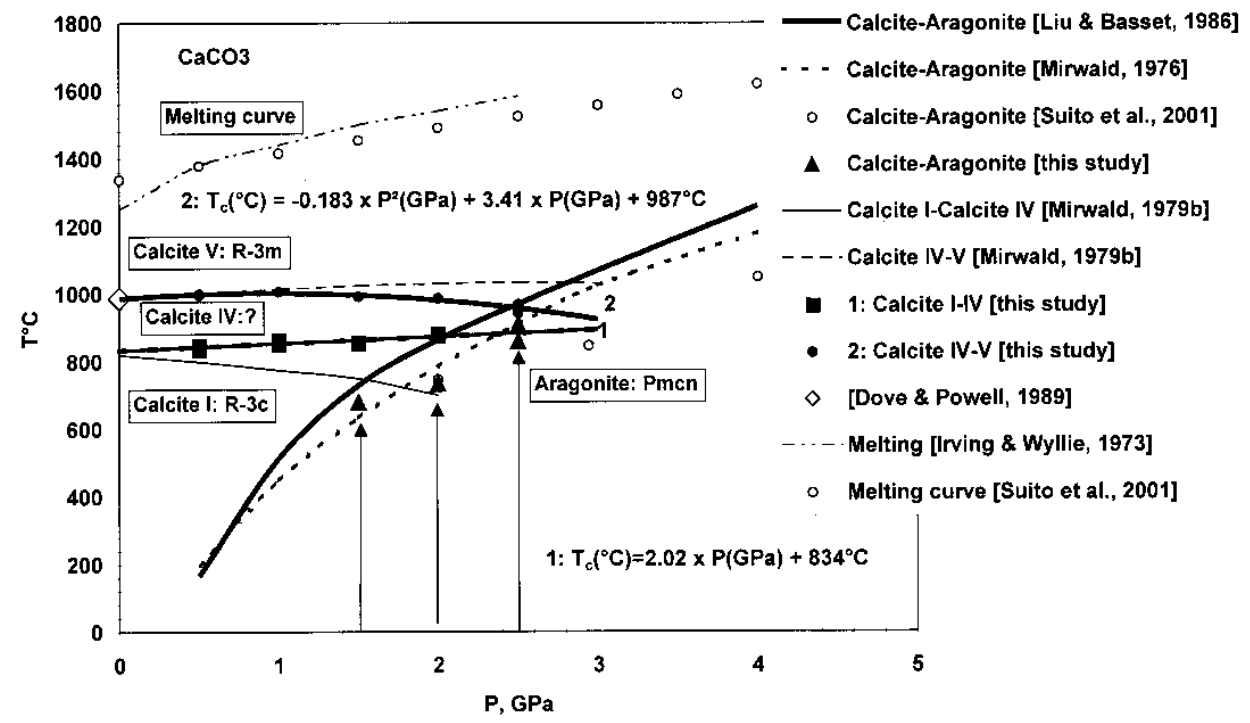

FIGURE 6 Phase diagram of $\mathrm{CaCO}_{3}$. Melting curve from Irving and Wyllie (1968) and Suito et al. (2001). The slope of Calcite IV $\Leftrightarrow R-3 c$ is positive (1). The slope of calcite $R-3 m \Leftrightarrow R-3 c$ phase transformation boundary at low pressure $(\Leftarrow 0.5 \mathrm{GPa})$ is close to the results of Cohen and Klement (1973). At $0.1 \mathrm{MPa}$ the transformation temperature $T_{c}=987^{\circ} \mathrm{C} \pm 5^{\circ}$ Dove and Powell (1989). The slope of $T_{c}$ from this study (2) varies from positive up to $1 \mathrm{GPa}$ to negative at $P>1 \mathrm{GPa}$. Arrows indicate the kinetic experiments performed near the calcite-aragonite phase boundary. Recent data of Suito et al. (2001) for calcite-aragonite boundary are in good agreement with the kinetical experiments of this study.

on geometry of nucleus and relative rate of nucleation and growth of a new phase (Carlson, 1983; Liu and Yound, 1993).

The estimated from experiments kinetic parameters $\tau$ in Eq. (5) of Calcite $\Rightarrow$ Aragonite transformation depends on temperature according to an Arrhenius dependence, parameter $m$ depends on $\delta P-\delta T$ deviation of a transformation point from the accepted phase equilibrium boundary. Far away from the transition boundary $m \approx 1$, at $\delta P-\delta T$ close to the calcite-aragonite boundary $m \approx 1.5$. This may interpreted that in the vicinity of the equilibrium boundary the overall kinetics is more affected by a nucleation process rather than by a growth rate.

\section{CONCLUSIONS}

1. Electrical impedance measurements may be successfully used to identify phase transition temperature $T$, at high pressures in calcite $\mathrm{R}-3 \mathrm{c} \Leftrightarrow \mathrm{R}-3 \mathrm{~m}$, between ordered and orientational disordered phases. The data indicate the decrease of $T_{c}$ at pressures above $1 \mathrm{GPa}$ (see Table I). This may be caused by a close location of calcite-aragonite phase boundary to $\mathrm{R}-3 \mathrm{c} \Leftrightarrow \mathrm{R}-3 \mathrm{~m}$ phase transition boundary as a consequence of a strong coupling between orientational and out-of-plane translational variables (order parameters) of these two phase transitions (Ferrario et al., 1994).

2. The phase transformation Calcite $\Leftrightarrow$ Calcite IV previously discussed in the literature (Mirwald, 1976, 1979a,b; Redfern et al., 1989) is difficult to identify from 
electrical conductivity data. It certainly has a kinetical character and disappears after a 2-d cycle of cooling-heating. This, probably kinetical, phase boundary depends on the thermal history of the calcite sample: cooling rate from the field of the disordered high temperature phase and annealing time of a sample at low temperatures. The closeness of the calcite-aragonite boundary make the kinetical phase Calcite IV vanishing at high pressure.

3. Kinetics of calcite $\Leftrightarrow$ aragonite transformation to a first order approximation may be estimated from a time dependence of the electrical bulk resistance. For example, at $1.5 \mathrm{GPa}$ and $680^{\circ} \mathrm{C}$ the characteristic transformation time $\tau$ is $\sim 8.8 \mathrm{~h}$, at $2.5 \mathrm{GPa}$ and $780^{\circ} \mathrm{C} \tau \sim 7.5 \mathrm{~h}$, at $2.5 \mathrm{GPa}$ and $910^{\circ} \mathrm{C} \tau \sim 0.5 \mathrm{~h}$, and at $2 \mathrm{GPa}$ and $735^{\circ} \mathrm{C}$ $\tau \sim 33 \mathrm{~h}$.

\section{Acknowledgements}

This work was funded by Special Program of German Science Foundation SPP 1150. A. S. thanks Exchange Program between GSF and Russian Academy of Sciences for covering his travel and stay costs in IfMG. The authors are grateful to R. Petscheck (IfPG, Frankfurt) for the diffractometer analysis of samples.

\section{References}

Bagdassarov, N., Freiheit, C.-H. and Putnis, A. (2001). Electrical conductivity and pressure dependence of trigonal-to-cubic phase transition in lithium sodium sulphate. Solid Sate Ionics, 143(3-4), 285-296.

Bogris, N., Grammatikakis, J. and Papathanassiou, A.N. (1998). Dipole and interfacial polarization in natural single-crystal calcite studied by the thermally stimulated depolarization current method. Phys. Rev. B., 58, 10319-10325.

Carlson, W.D. (1983). The polymorphs of $\mathrm{CaCO}_{3}$ and the aragonite-calcite transformation. In: Reeder, R.J. (Ed.), Carbonates: Mineralogy and Chemistry. Reviews in Mineralogy, Vol. 11, pp. 191-225. Mineralogical Society of America.

Crawford, W.A. and Fyfe, W.S. (1964). Calcite-aragonite equilibrium at $100^{\circ}$ C. Science, 144, 1569-1570.

Crawford, W.A. and Hoersch, A.L. (1972). Calcite-aragonite equilibrium from $50^{\circ} \mathrm{C}$ to $150^{\circ} \mathrm{C}$. Amer. Mineralogist, 157, 995-998.

Cohen, L.H. and Klement, W. Jr. (1973). Determination of high-temperature transition in calcite to $5 \mathrm{kbar}$ by differential thermal analysis in hydrostatic apparatus. J. Geology, 81, 724-727.

Dove, M.T. (1997). Theory of displacive phase transitions in minerals. Amer. Mineralogist, 82, $213-244$.

Dove, M.T. and Powell, B.M. (1989). Neutron diffraction study of the tricritical orientational order/disorder phase transition in calcite at $1260 \mathrm{~K}$. Phys. Chem. Minerals, 16, 503-507.

Ferrario, M., Lynden-Bell, R.M. and McDonald, I.R. (1994). Structural fluctuations and the order-disorder phase transition in calcite. J. Phys. Condens. Matter, 6, 1345-1358.

Grammatikakis, J., Manolopoulos, M. and Papathanassiou, A.N. (2001). Dielectric relaxation in calcite by piezostimulated depolarization-current spectroscopy. Phys. Rew. B, 65, 331011-331013.

Hacker, B.R., Kirby, S.H. and Bohlen, S.R. (1992). Time and metamorphic petrology: calcite to aragonite experiments. Science, 258, 110-112.

Hagen, M., Dove, M.T., Harris, M.J., Steigenberger, U. and Powell, B.M. (1992). Orientational orderdisorder phase transition in calcite. Physica B, 180-181, 276-278.

Honma, K., Yoshinaka, M., Hirota, K. and Yamaguchi, O. (1998). Fabrication of calcite $\left(\mathrm{CaCO}_{3}\right)$ ceramics with high density. J. Material Sci. Lett., 17, 745-746.

Hosoi, K., Hashida, T., Takehashi, H., Yamasaki, N., and Korenga, T. (1996). Low temperature solidification of carbonate through vatenite-calcite transformation. J. Material Sci. Lett., 15, 812-814.

Hosoi, K., Hashida, T., Takahaski, H., Yamasaki, N. and Korenaga, T. (1997). Solidfication of calcium carbonate via aragonite-calcite wet transformation with hydrothermal pressing. J. Material Sci. Lett., 16, 382-385.

Israeloff, N.E. (1996). Dielectric polarization noise through the glass transition. Phys. Rev. B: Condens. Matt., 53(18), R11913-R11916. 
Irving, A.J. and Wyllie, P.J. (1973). Melting relationships in $\mathrm{CaO}-\mathrm{CO}_{2}$ and $\mathrm{MgO}-\mathrm{CO}_{2}$ to 36 kbars with comments on $\mathrm{CO}_{2}$ in the mantle. Earth Planet Sci. Lett., 20, 220-225.

Jamieson, J.C. (1953). Phase equilibrium in the system calcite aragonite. J. Chem. Phys., 21, 1385-1390.

Johannes, W. and Puhan, D. (1971). The calcite-aragonite transition, reinvestigated. Contrib. Mineral Petrol, 31, 28-38.

Jonscher, A.K. (1999a). Dielectric relaxation in solids. J. Phys. D: Appl. Phys., 32, R57-R70.

Jonscher, A.K. (1999a). Low-loss dielectrics. J. Material Sci., 34, 3071-3082.

Lander, J.J. (1949). Polymorphism and anion rotational disorder in the alkaline earth carbonates. J. Chem. Phys., 17, 893-901.

Liu, M. and Yund, R.A. (1993). Transformation kinetic of polycrystalline aragonite to calcite: new experimental data, modelling, and implications. Contrib. Mineral Petrol, 114, 465-478.

Mandell, G.K. and Rock, P.A. (1998). Lattice energies of calcite-structure metal carbonates II. Results for $\mathrm{CaCO}_{3}, \mathrm{CdCO}_{3}, \mathrm{FeCO}_{3}, \mathrm{MgCO}_{3}$ and $\mathrm{MnCO}_{3}$. J. Phys. Chem. Solids, 59, 703-712.

Mirwald, P.W. (1976). A differential thermal analysis study of the high-temperature polymorphism of calcite at high pressure. Contrib. Mineral Petrol, 59, 33-40.

Mirwald, P.W. (1979a). Determination if a high-temperature transition of calcite $800^{\circ} \mathrm{C}$ and one bar $\mathrm{CO}_{2}$ pressure. N. Jb. Miner. Mh., 7, 309-315.

Mirwald, P.W. (1979b). The electrical conductivity of calcite between 300 and $1200^{\circ} \mathrm{C}$ at $\mathrm{CO}_{2}$ pressure 40 bars. Phys. Chem. Minerals, 4, 291-297.

Padlewski, S., Evans, A.K., Ayling, C. and Heinet, V. (1992). Crossover between displacive and order/ disorder behaviour in $\Phi^{4}$ model. J. Phys.: Condense Matter, 4, 4895-4908.

Rao, K.S. and Rao, K.V. (1968). Dielectric dispersion and ties temperature variation in calcite single crystals. Zeitrschr für Physik., 216, 300-306.

Redfern, S.A.T., Salje, E. and Navrotsky, A. (1989). High-temperature enthalpy at the orientational orderdisorder transition in calcite: implications for the calcite/aragonite phase equilibrium. Contrib. Mineral Petrol, 101, 479-485.

Sidebottom, D.L., Green, P.F. and Brow, R.K. (1995). Two contributions to the AC conductivity of alkali oxide glasses. Phys. Rev. Letters, 74, 5068-5071.

Simmons, G. and Bell, P. (1963). Calcite aragonite equilibrium. Science, 139, 1197-1198.

Slutskii, A.B. (1969). An apparatus for studing the effect of high pressure and high temperature on the electrical conductivity of solid dielectrics. Pribory $i$ Tekhnika Eksperimenta, 6, 183-185 (in Russian).

Suito, K., Namba, J., Horokawa, T., Tanigichi, Y., Sakurai. N., Kobayashi, M., Onodera, A., Shimomura, O. and Kikegawa, T. (2001). Phase relations of $\mathrm{CaCO}_{3}$ at high pressure and temperature. Amer. Mineral, 86, 997-1002.

Zimmerman, H.D. (1971). Equilibrium conditions for calcite/aragonite reaction between $150^{\circ} \mathrm{C}$ and $350^{\circ} \mathrm{C}$. Nature Physical Science, 231, 203-204. 